\title{
Impactos socioeconômicos do cultivo de camarão marinho em municípios selecionados do Nordeste brasileiro
}

\author{
Yony Sampaio ${ }^{1}$ \\ Ecio de Farias Costa ${ }^{2}$ \\ Erica Albuquerque \\ Breno Ramos Sampaio ${ }^{3}$
}

Resumo: Neste trabalho, analisa-se o impacto do camarão marinho cultivado sobre a economia de dez municípios selecionados do Nordeste brasileiro. Para tanto, foi desenvolvido o modelo da economia municipal e são usadas matrizes de insumo-produto para calcular os impactos indiretos e induzidos. São calculados os impactos diretos, indiretos e induzidos sobre o emprego, sobre a renda municipal e sobre a arrecadação municipal. Constata-se que há grande contribuição para a expansão do emprego municipal, principalmente do emprego formal. Os impactos indiretos e induzidos são reduzidos, uma vez que os desdobramentos da atividade se interligam com municípios maiores e outros estados e regiões. Os impactos sobre a renda podem ser de grande magnitude nos municípios menores. De modo geral, a renda gerada representa parcela substancial do PIB municipal. Quanto à arrecadação, a contribuição para o aumento da receita tributária é pequena, mas a contribuição, via valor agregado e exportações, para as transferências da cota-parte do ICMS e compensatória da isenção das exportações é substancial. Em conseqüência, pode-se concluir que a carcinicultura, nos municípios analisados, contribui para a elevação e a estabilidade do emprego, para

\footnotetext{
${ }^{1}$ Professor Titular de Economia, Departamento de Economia/Pimes, UFPE. Ph.D. em Economia, Universidade da Califórnia, 1973. E-mail: sampyony@yahoo.com.br

${ }^{2}$ Professor Adjunto II de Economia, Departamento de Economia/Pimes, UFPE. M.S. e Ph.D em Economia Agrícola, University of Georgia, 2001. E-mail: ecio@yahoo.com

${ }^{3}$ Doutorando em Economia, Universidade de Illinois. E-mail: brenosampaio@hotmail.com
} 
a elevação e a estabilidade da renda, para a elevação da receita municipal e para a melhoria das condições de vida.

Palavras-chave: Camarão marinho cultivado; impactos municipais; impactos diretos; indiretos e induzidos; emprego; renda; arrecadação.

Abstract: This paper analyses the impact of farmed shrimp on the economy of ten municipalities in the Northeast of Brazil. A model of the municipal economy is developed and input-output tables are used to estimate indirect and induced impacts on job, income and municipal finances. It is concluded that farmed shrimp has a sizable contribution to job increases, in particular formal employment. Indirect and induced impacts are reduced because of spillovers to larger municipalities and other states. Income impacts can be sizable in particular in small counties. In general, the generated income represents a large share of total municipal product. In relation to municipal finance, direct contribution is rather small but indirect, through product increases and mainly transferences from State and Country taxes may be substantial. In conclusion, shrimp farms in the selected municipalities, contributes to expand and stabilize employment, to expand income and product, to increase municipal finances and to improve life conditions.

Key-words: farmed shrimp; municipal level impacts; direct; indirect and induced impacts; job; income; tax impacts.

Classificação JEL: Q10, Q22, R11.

\section{Introdução}

A expansão da carcinicultura no Brasil destacou-se pela velocidade de ampliação da área ocupada pelas fazendas de engorda, do número de fazendas, da produção e das exportações (Rocha, Rodrigues e Amorim, 2004; Costa, Sampaio e Albuquerque, 2004). O resultado foi uma substancial geração de emprego e absorção da população local com baixa instrução formal (Costa e Sampaio, 2003). Sabe-se, por outro lado, que a atividade é concentrada em alguns municípios e que, nestes, deve ter 
impacto destacado sobre o emprego e a renda municipal. A elevação da renda, por sua vez, deve repercutir no aumento da arrecadação municipal, direta e indireta, proporciando condições para maior investimento social, para melhoria da rede escolar e dos serviços de saúde, por exemplo. A renda mais elevada e o emprego propiciam ampla possibilidade de aumento nos níveis de consumo e bem-estar da população desses municípios.

Pesquisa qualitativa realizada em municípios selecionados constata que há amplo reconhecimento da expansão do emprego. Quando perguntados sobre o principal efeito da carcinicultura no município, a resposta unânime é: aumento no emprego. Além da magnitude, são empregos estáveis e que privilegiam a população local, porque não requerem educação formal elevada. Com um maior questionamento, destaca-se o impacto na renda do município, principalmente no comércio. Por fim, uma parcela da população, com maior reflexão, destaca o impacto do emprego no nível de vida da população, pelo lado da demanda: "com mais emprego e renda, as casas são melhoradas, a saúde está melhor, o nível de vida se eleva”.

Este trabalho se volta para a análise dos impactos socioeconômicos do cultivo do camarão marinho em alguns municípios selecionados do Nordeste brasileiro. Os impactos diretos e indiretos sobre empregos, renda e tributação que a carcinicultura gera nos municípios selecionados são analisados, segmentando-os nos municípios analisados e nos que impactam outros municípios.

Além da introdução, o estudo é composto de mais seis seções. Na segunda, é apresentada a cadeia produtiva do camarão cultivado e são fornecidos dados que situam a importância da atividade nos municípios. Na terceira, são detalhados o modelo, os métodos e os dados. Na quarta, estima-se o impacto sobre o emprego. Na quinta seção, calculase o impacto sobre a renda e, na sexta, o impacto sobre a arrecadação municipal. Por fim, na última seção, estão colocadas as conclusões e algumas inferências.

\section{Municípios pesquisados}


Impactos socioeconômicos do cultivo de camarão marinho em municípios selecionados do Nordeste brasileiro

O fluxograma na Figura 1 apresenta os três elos diretamente envolvidos na cadeia produtiva do camarão marinho cultivado: os laboratórios de larvicultura, nos quais são produzidos as pós-larvas; as fazendas de engorda, responsáveis pelo ciclo de desenvolvimento do camarão e os centros de processamento, que preparam o produto para o mercado nacional e de exportação, ressaltando que este último é responsável por mais de $62 \%$ do destino do camarão brasileiro processado. À cadeia, conectam-se os segmentos industriais produtores de rações, de insumos para preparo de viveiros (e.g., fertilizante e calcáreo), de equipamentos (e.g., aeradores, bombas, motores, equipamentos de aferição da qualidade da água, entre outros) e o segmento de serviços (e.g., energia e transporte e, principalmente os serviços portuários). A atividade e suas ligações para frente e para trás na cadeia produtiva definem o começo dos impactos diretos e indiretos gerados; as interligações, em matriz insumo-produto, incluindo o vetor de demanda final, completam os impactos totais. A análise concentra-se em municípios selecionados e analisa os impactos que são retidos nestes municípios.

Figura 1. Fluxograma da cadeia produtiva do camarão marinho cultivado

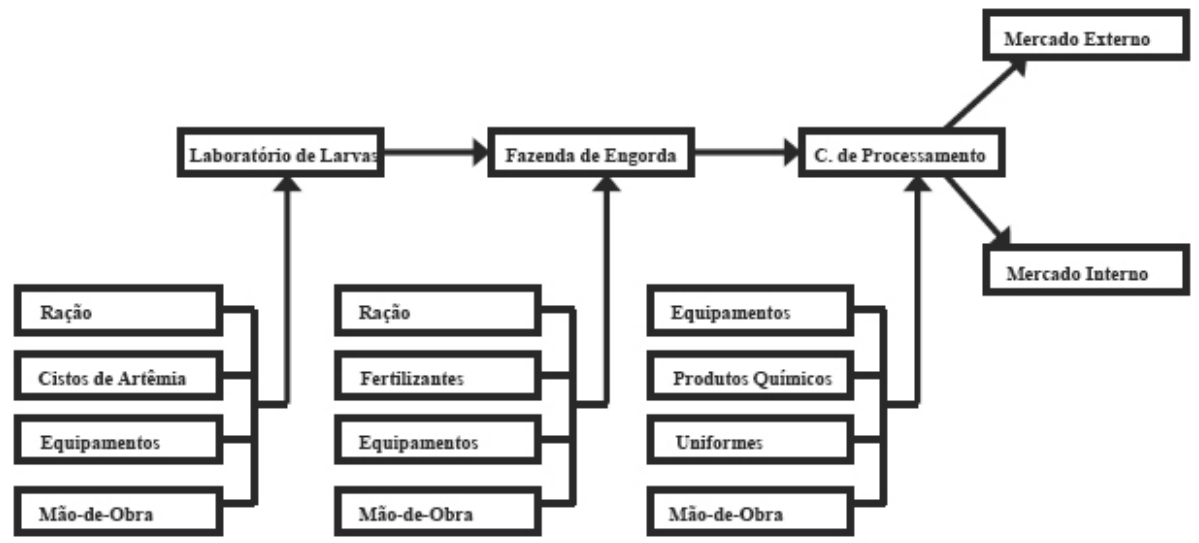

Fonte: Elaboração própria.

Foram selecionados dez municípios para análise: Cajueiro da Praia, no Piauí; Acaraú e Aracati, no Ceará; Canguaretama, Pendências e Porto 
do Mangue, no Rio Grande do Norte; Goiana e Itapissuma, em Pernambuco; e Jandaíra e Valença, na Bahia. Esses dez municípios representam boa parte da produção de camarão cultivado em seus respectivos estados. Na Tabela 1, tem-se uma primeira visão da representatividade. No estado do Piauí, o município de Cajueiro da Praia possui metade das fazendas e da área em produção. No Ceará, Acaraú e Aracati somados, representam $36 \%$ do número de fazendas e $52 \%$ da área cultivada. No Rio Grande do Norte, a representatividade é menor, uma vez que este é o maior produtor nacional e atualmente tem a atividade bastante dispersa ao longo do litoral. Não obstante, os três municípios representam $14 \%$ das fazendas e $46 \%$ da área, concentrando quase metade da área em produção. Em Pernambuco, os dois municípios concentram apenas nove fazendas, $12 \%$ do total, mas $78 \%$ da área. Na Bahia, à semelhança de Pernambuco, têm-se seis fazendas, ou $14 \%$ do total, mas que produzem $67 \%$ do camarão cultivado do estado. Com relação ao número de laboratórios de pós-larvas, no Ceará, Acaraú e Aracati somados, representam $75 \%$ do total. Na Bahia, Valença e Jandaíra, a participação dos laboratórios é de $50 \%$. No Piauí, Cajueiro da Praia, estão concentrados $33 \%$ dos laboratórios. No Rio Grande do Norte, por conta da atividade ser dispersa, Canguaretama, Pendências e Porto do Mangue representam 25\% do total. Já em Pernambuco, não há laboratórios nos dois municípios analisados. Quanto aos centros de processamento, a amostra tem maior representatividade na Bahia, que em Valença e Jandaíra, juntos, apresentam $40 \%$ do número de centros de processamento instalados naquele estado. Em seguida, aparecem os estados do Rio Grande do Norte, Piauí e Ceará, com 33\%, $25 \%$ e $20 \%$, respectivamente, do número de centros de processamento instalados naqueles estados. Quanto ao estado de Pernambuco, apenas o município de Goiana possui um centro de processamento. Essa menor concentração de centros de processamento nos municípios pesquisados devese ao fato de que grandes centros de processamento já encontravam-se previamente estabelecidos em cidades próximas às da amostra durante o processo de desenvolvimento recente da carcinicultura. Esses centros já eram responsáveis pelo processamento, e, às vezes, beneficiamento de pescados. Então, gerou-se todo um reaproveitamento desses centros para o processamento do camarão marinho cultivado. Além disso, o 
processamento ocorre em geral próximo aos locais de comercialização e de exportação.

Tabela 1. Fazendas, laboratórios e centros de processamento de estados e municípios selecionados, 2003

\begin{tabular}{|l|l|c|c|c|c|}
\hline \multirow{2}{*}{ Estado } & \multirow{2}{*}{ Município } & \multicolumn{2}{|c|}{ Fazendas } & Laboratórios & $\begin{array}{c}\text { Centros de } \\
\text { Processamento }\end{array}$ \\
\cline { 3 - 6 } & & $\mathrm{N}^{\circ}$ & Área (ha) & $\mathrm{N}^{\circ}$ & $\mathrm{N}^{\circ}$ \\
\hline Piauí & & 16 & 687 & 3 & 4 \\
\hline & Cajueiro da Praia & 8 & 340 & 1 & 1 \\
\hline Ceará & & 185 & 3.377 & 4 & 10 \\
\hline & Acaraú & 16 & 708 & 1 & 1 \\
\hline & Aracati & 50 & 1.037 & 2 & 1 \\
\hline $\begin{array}{l}\text { Rio Grande } \\
\text { do Norte }\end{array}$ & & 362 & 5.402 & 12 & 9 \\
\hline & & 40 & 750 & 3 & 2 \\
\hline & Canguaretama & 8 & 980 & 0 & 1 \\
\hline & Pendências & 3 & 739 & 0 & 0 \\
\hline Pernambuco & & 79 & 1.130 & 3 & 4 \\
\hline & Goiana & 6 & 610 & 0 & 1 \\
\hline & Itapissuma & 3 & 275 & 0 & 0 \\
\hline Bahia & & 42 & 1.737 & 8 & 5 \\
\hline & Valença & 5 & 765 & 3 & 1 \\
\hline & Jandaíra & 1 & 395 & 1 & 39 \\
\hline Nordeste & & 825 & 13.644 & 32 & \\
\hline
\end{tabular}

Fonte: Elaboração própria a partir de ABCC (2004).

Detalhando mais a participação dos municípios, confirma-se a importância das fazendas na produção estadual, que é de $82 \%$ na Bahia, passando por $75 \%$ em Pernambuco, $56 \%$ no Ceará, $52 \%$ no Rio Grande do Norte, e de $49 \%$ no Piauí.

Os laboratórios, quando vistos pela produção de pós-larvas, adquirem importância maior no Ceará (84\%), na Bahia (71\%), no Piauí (66\%) e no Rio Grande do Norte (49\%). Em Pernambuco, não há laboratórios nos municípios analisados. Porém, em outros municípios, há laboratórios com grande expressão em termos nacionais.

Os centros de processamento, nestes municípios, representam per- 
centuais, em relação ao estado, de $99 \%$ na Bahia, de $44 \%$ em Pernambuco, 43 \% no Ceará, $42 \%$ no Rio Grande do Norte e 37\% no Piauí. Esses percentuais são inferiores aos da produção, com exceção da Bahia. Tal constatação decorre do fato de parte do processamento ocorrer próximo aos portos de exportação. Em função do destino (Estados Unidos ou União Européia), o camarão é processado sem cabeça ou inteiro. Em Cajueiro da Praia, 95\% do camarão é processado inteiro. Em Acaraú, predomina o processamento do camarão sem cabeça (90\%) e em Aracati, o camarão inteiro (90\%). Em Canguaretama e em Jandaíra, 80\% e $100 \%$, respectivamente, do camarão é processado inteiro, sendo que em Valença, o processamento dividiu-se entre inteiro e sem cabeça.

Esses números revelam, em uma abordagem inicial, que os efeitos sobre o emprego direto da carcinicultura, nestes estados, concentram-se nos municípios selecionados, já que estão mais diretamente ligados às fazendas de criação e engorda e são proporcionais à área em exploração. O efeito-renda direto é menor, uma vez que a agregação de valor e a comercialização ocorrem em outros municípios. Ou seja, apenas uma fração da renda é retida e gasta no município, gerando impactos diretos na renda e indiretos sobre o emprego (induzido, via gasto), sobre a própria renda (via gasto, através dos multiplicadores de renda, com grande impacto no comércio em geral), e sobre a arrecadação municipal (efeitos indiretos que movimentam outras atividades e expandem indiretamente a arrecadação direta pelo município e expandem o valor agregado e as transferências do Estado e da União).

De modo geral, as ligações para trás e para adiante, via aquisição de insumos e processamento, comercialização e consumo da produção, mostradas na Figura 1, ocorrem predominantemente fora do município. Tanto os impactos indiretos do emprego como os da renda, de substancial magnitude, não são retidos nesses municípios.

Para uma visão mais sólida dos impactos da carcinicultura no município é necessário estabelecer modelo que integre e explique os efeitos diretos, indiretos e induzidos sobre o emprego, sobre a renda, sobre as finanças municipais e, em ultima análise, sobre o nível de vida das populações neles residentes.

\section{Modelo de impacto da carcinicultura em termos municipais, dados e métodos}


A Figura 2, que representa a rede de causalidades que liga a carcinicultura ao nível de vida no município, mostra ser necessário determinar os efeitos da carcinicultura em termos municipais por meio de um modelo que leve em consideração os efeitos diretos e indiretos inerentes à atividade. Porém, é necessário também que se determine o que realmente fica no município em termos de impactos, principalmente indiretos. Muitos dos efeitos tendem a se dispersar por outros municípios, principalmente por aqueles que são grandes representantes de dois elos produtivos desta cadeia: os elos de fornecimento de insumos e agregação de valor.

A carcinicultura afeta a renda municipal e o nível de vida da população de forma direta e indireta. De modo direto, gera emprego e renda, sendo a renda a soma da folha salarial e das demais despesas do município. Contribui, também, com impostos municipais, diretamente por alvarás e impostos sobre serviços (ISS) - e indiretamente, via transferências estaduais e federais. De modo indireto, impacta, via ligações, com supridores de insumos localizados no município, e processadores e comerciantes da produção gerada. Também por modo indireto, via indução, a renda gerada integra uma rede que multiplica os efeitos diretos pelo consumo - estimula o comércio, que demanda produtos, emprega e paga impostos. Tudo somado, o PIB municipal é acrescido pelo produto gerado de forma direta e indireta. O acréscimo de arrecadação propicia aumento nos gastos do governo municipal, integrando uma nova cadeia de multiplicadores do emprego e da renda. Por fim, de um lado, a expansão direta, indireta e induzida, pelas diversas formas, do emprego e da renda, impacta a demanda por bens e serviços ligados à melhoria da qualidade da vida (habitação, serviços de saúde e educação, alimentação, etc.); de outro lado, estimula a ampliação da oferta de serviços, tanto privados quanto públicos.

Figura 2. Descrição do modelo de capitação dos efeitos da carcinicultura a 
nível municipal

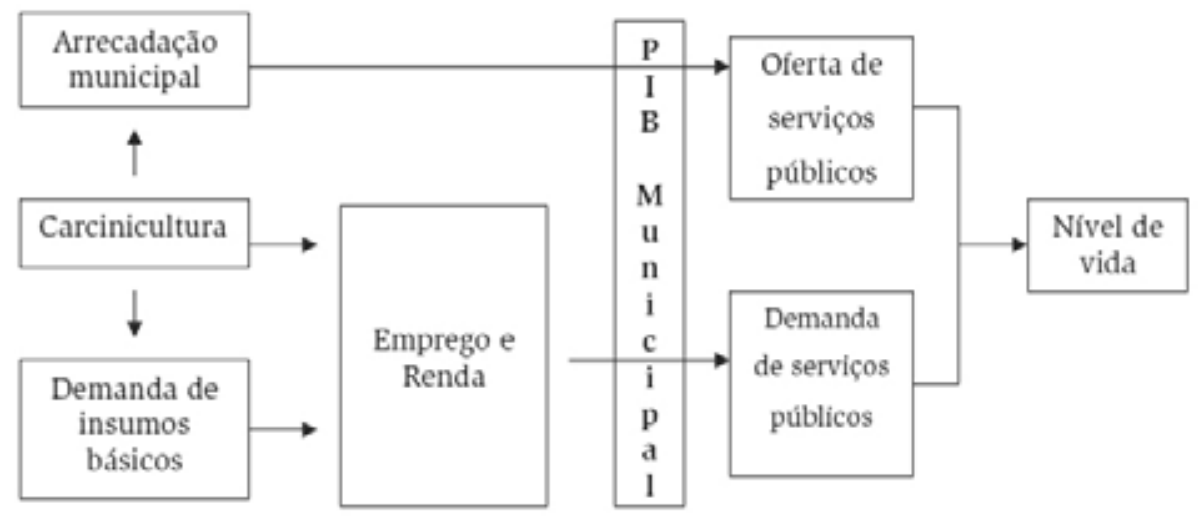

Fonte: Elaboração própria.

Para análise dos impactos da carcinicultura, são adotadas várias simplificações. Supõe-se que o consumo é função da renda (por simplificação, do produto): $\mathrm{C}=\mathrm{f}(\mathrm{Y})$, e que os tributos diretos sejam função do produto municipal: $\mathrm{Td}=\mathrm{Td}(\mathrm{Y})$. As transferências dos governos federal e estadual também são afetadas pela produção municipal (valor agregado, no caso do ICMS, por exemplo). Assume-se que a carcinicultura afeta a renda municipal (Y), através das remunerações (novos empregos/folha salarial e impactos indiretos), dos lucros e da receita do governo. Somando-se os impactos diretos e indiretos sobre a renda, tem-se Y. A contribuição na tributação direta, (Td), pode ser obtida pela incidência de impostos municipais sobre a atividade. A estimação do impacto sobre os tributos diretos é feita com base na arrecadação dos tributos municipais. Para efeito de estimação, estes foram desagregados em tributos incidentes diretamente na atividade da carcinicultura e outros tributos diretos, como o imposto sobre serviços, considerados função do produto. Os tributos incidentes diretamente na atividade foram obtidos junto às secretarias de finanças dos municípios e os outros, estimados a partir da participação da renda gerada na renda total do município.

O cálculo da renda direta gerada em termos municipais considera as condições particulares de cada município. A renda total é a soma do 
valor da produção, em termos municipais. A renda retida no município é a soma da folha salarial paga, dos insumos comprados a nível municipal e da parcela da renda líquida dos produtores e empresas gasta no município. Assume-se que essa parcela da renda líquida é integral no caso de apenas dois municípios: Acaraú e Aracati, os quais apresentam comércio local diversificado e empresas de base local, isto é, as maiores empresas operando na carcinicultura são de grupos locais. Nos outros municípios, assumiu-se que só as pequenas fazendas, cujos proprietários residem nos municípios, retêm e consomem a sua renda. A maior parte das despesas com insumos é "exportada” para fora do município. A renda total gerada é assim separada entre a retida no município e a exportada para outros municípios.

A renda indireta é obtida com base na matriz de insumo-produto para o Nordeste (BNB, 2001) e, principalmente, no trabalho de Rodriguez e Guilhoto (1998), que abriram um setor de pesca, aqüicultura e carcinicultura, o qual aproxima bastante as ligações para trás e para adiante do agronegócio do camarão marinho cultivado. Diversos ajustes foram necessários, como abaixo explicitado.

Inicialmente, a renda direta gerada, $\mathrm{Xn}$, foi particionada, $\mathrm{Xn}=\mathrm{Xni}$ + Xnj, em que, Xni é o valor agregado retido no município e Xnj é o valor agregado gasto fora do município.

Como conseqüência, o vetor de multiplicadores de renda e emprego é igualmente particionado. Para o caso da renda, $\mathrm{Y}=\sum$ ai bi $+\sum$ aj bj, em que, ai é um elemento da linha na matriz correspondente à renda e bi representa os elementos da matriz inversa de Leontief [( $\left.\mathrm{I}-\mathrm{A})^{-1}\right]$.

É conhecido que essa partição gera uma sobreestimativa da renda e do emprego indiretos, uma vez que exclui os dispêndios e inter-relações que se dão fora do município, mas considera que os gastos que ocorrem no município geram seus efeitos integralmente no município, o que não é verdadeiro. Essa é, no entanto, a melhor estimativa possível, a nível municipal.

Foi considerada a origem de cada insumo/consumo ocorrido em termos de fazenda de engorda, laboratório e centro de processamento, para isolar os setores da matriz que representam dispêndios municipais. A origem foi obtida em pesquisa direta junto aos produtores e processadores.

Com base nos valores particionados, é calculada a renda indireta, 
usando metodologia tradicional da análise de insumo-produto. Tomando o caso da renda, a matriz de insumo-produto do modelo fechado de Leontief pode ser definida como:

$$
A^{*}=\left[\begin{array}{ll}
A & c^{\prime} \\
c^{\prime} y & 0
\end{array}\right]
$$

Em que, A é a matriz de coeficientes técnicos de Leontief, C é o vetor da estrutura setorial de consumo marginal e c'y é o vetor de propensões marginais a consumir.

Tomando-se o vetor de coeficientes de valor agregado por unidade de produção (y), define-se 0 como o vetor equivalente do modelo fechado de Leontief,

$$
\mathrm{y}^{*}=(\mathrm{y}: 0)
$$

Os requerimentos diretos e indiretos (de insumos e consumo) de renda por unidade de produção são dados por:

$$
\mathrm{Y}^{*}=\mathrm{y}^{*}\left(\mathrm{I}-\mathrm{A}^{*}\right)^{-1}
$$

A carcinicultura gera uma demanda adicional de insumos e consumo intermediários sobre n setores,

$$
\mathrm{X}^{\mathrm{a}}=\left[\mathrm{X}_{1}^{\mathrm{a}}, \mathrm{X}_{2}^{\mathrm{a}}, \ldots, \mathrm{X}_{\mathrm{n}}^{\mathrm{a}}\right]
$$

A qual é ainda segmentada em Xi e Xj, representando a demanda gerada dentro e fora do município.

Dessa forma, o impacto indireto, de insumos e consumo, sobre a renda, é dado por $\mathrm{Y}^{*} \mathrm{X}^{\mathrm{a}}$. Somando-se a este impacto indireto o impacto direto no próprio setor, obtém-se o impacto total (direto e indireto) da carcinicultura sobre a renda, 


$$
\mathrm{Y}^{\mathrm{t}}=\mathrm{Y}^{\mathrm{a}}+\mathrm{Y}^{*} \mathrm{X}^{\mathrm{a}}
$$

o qual é separado em dentro e fora do município.

De igual modo foi procedido em relação aos impactos indiretos e total sobre o emprego.

O ano base, para o qual foram obtidos dados do Censo da Carcinicultura, elaborado pela ABCC, é 2003. Esses dados básicos incluem informações sobre as fazendas de engorda, de laboratórios e de centros de processamento em cada município, principalmente dados sobre a produção. Preços médios para os mercados interno e externo foram fornecidos pela ABCC, por produtores e referidos na Revista da ABCC (vários números). Quanto aos insumos, foram utilizados dados primários coletados pelos autores junto a fazendas de engorda, laboratórios e centros de processamento. Adicionalmente, foram cotejados com dados apresentados por Souza Júnior (2003). Informações adicionais foram coletadas junto a esses agentes da cadeia produtiva nas visitas a cada município. Dados sobre a arrecadação municipal foram coletados junto às prefeituras e, sobre transferências estaduais, junto às Secretarias Estaduais da Fazenda. Dados sobre finanças municipais foram obtidos no site do Ministério da Fazenda. Adicionalmente, foram utilizados dados secundários do IBGE e da RAIS. O PIB municipal foi estimado usando metodologia desenvolvida pelo Instituto de Pesquisa Econômica Aplicada (Ipea) (Vergolino e Maia Gomes, 1999).

\section{Impactos diretos e indiretos sobre o emprego municipal}

O emprego direto formal total de responsabilidade da carcinicultura, por município, obtido no Censo Anual realizado pela ABCC, para 2003, é apresentado na Tabela 2, destacando-se o emprego direto nas fazendas, nos laboratórios e nos centros de processamento. Em vários municípios, a carcinicultura é o setor responsável, individualmente, por maior geração de emprego. É o caso de Cajueiro da Praia, no qual o segundo setor é a prefeitura. O mesmo ocorre em Valença, Jandaíra, Pendências e Porto do Mangue. 
Tabela 2. Emprego direto gerado nos municípios, 2003

\begin{tabular}{|l|c|c|c|c|}
\hline Município & Fazendas & Laboratórios & CP's & Total \\
\hline Cajueiro da Praia & 253 & 34 & 76 & 363 \\
\hline Acaraú & 513 & 55 & 131 & 699 \\
\hline Aracati & 1.180 & 86 & 480 & 1.746 \\
\hline Canguaretama & 817 & 254 & 320 & 1.391 \\
\hline Pendências & 1.764 & - & 225 & 1.989 \\
\hline Porto do Mangue & 715 & - & - & 715 \\
\hline Goiana & 264 & - & 261 & 525 \\
\hline Itapissuma & 292 & - & - & 292 \\
\hline Valença & 297 & 61 & 472 & 830 \\
\hline Jandaíra & 154 & 54 & 230 & 438 \\
\hline
\end{tabular}

Fonte: Elaboração própria a partir de dados do Censo da ABCC (2003).

O emprego total gerado (direto, indireto e induzido) é apresentado tanto em número absoluto como em percentual da População Economicamente Ativa (PEA) (Tabela 3) (IBGE, 2005).

Para comparação, são dados o emprego indireto e induzido total e o que ocorre no município (colunas 1 e 2, Tabela 3 ). O emprego indireto e induzido total foi obtido com uso da matriz de insumo-produto; o retido, com uso da matriz particionada. Como destacado na metodologia, apenas a parte menor das ligações inter-setoriais tem impacto intramunicipal e mesmo com viés para cima, decorrente do método empregado, o emprego indireto e induzido que ocorre no município gerador varia de menos de $7 \%$ a um máximo de $69 \%$.

Em todos os municípios, a carcinicultura já é uma das atividades mais destacadas na geração de emprego. A exceção é Goiana, devido à expressão da indústria sucroalcooleira e ao fato de ser um pólo comercial de destaque.

Em relação à PEA, os percentuais, necessariamente, são bem menores, inclusive por que o desemprego e, principalmente, o sub-emprego, são muito expressivos. Ainda assim, em cinco municípios, a carcinicul- 
tura tem expressão significativa: Porto do Mangue, Pendências, Canguaretama, Cajueiro da Praia e Aracati. Apenas no município de Goiana, a participação na PEA total é muito pequena.

Tabela 3. Emprego total (direto, indireto e induzido) gerado - e indireto e induzido apenas no município, 2003

\begin{tabular}{|l|c|c|c|c|}
\hline Município & $\begin{array}{c}\text { Indireto e Induzido } \\
\text { Total }\end{array}$ & $\begin{array}{c}\text { Apenas no } \\
\text { Município }\end{array}$ & $\begin{array}{c}\text { Emprego Gerado } \\
\text { Total pela Carcini- } \\
\text { cultura }^{1}\end{array}$ & $\begin{array}{c}\text { \% da } \\
\text { PEA }\end{array}$ \\
\hline Cajueiro da Praia & 515 & 79 & 442 & 12,4 \\
\hline Acaraú & 1.649 & 1.132 & 1.831 & 6,7 \\
\hline Aracati & 2.981 & 1.911 & 3.657 & 9,8 \\
\hline Canguaretama & 2.398 & 544 & 1.935 & 12,8 \\
\hline Pendências & 2.233 & 180 & 2.169 & 30,9 \\
\hline Porto do Mangue & 1.618 & 110 & 825 & 34,5 \\
\hline Goiana & 988 & 104 & 629 & 1,4 \\
\hline Itapissuma & 410 & 33 & 325 & 2,6 \\
\hline Valença & 1.085 & 165 & 995 & 2,1 \\
\hline Jandaíra & 1.052 & 145 & 583 & 10,7 \\
\hline
\end{tabular}

Fonte: Elaboração Própria.

${ }^{1}$ No município, soma do emprego direto, do indireto e induzido apenas no município.

Em municípios mais litorâneos, nos quais a agropecuária tem menor expressão, a carcinicultura tem grande representatividade no emprego no setor, de acordo com dados da RAIS (Ministério do Trabalho, 2005): $100 \%$ em Cajueiro da Praia, acima de 90\% em Acaraú, Aracati, Itapissuma e Jandaíra, quase $80 \%$ em Valença, em torno de $60 \%$ em Pendências, entre $40 \%$ e $50 \%$ em Canguaretama e Porto do Mangue, e cerca de $20 \%$ em Goiana. Os dados da RAIS permitem a constatação de que a carcinicultura tem importância crescente, no emprego formal, de 1999 a 2003, acompanhando a expansão das fazendas, da área ocupada e da produção.

Pode-se concluir que, não obstante os impactos indiretos e induzidos escorrerem para fora do município, a carcinicultura tem grande expressão no emprego formal em quase todos os municípios, com exceção de Goiana, e em relação à PEA, novamente a exceção é Goiana. Confirma-se, com esse resultado, a expressão social da carcinicultura, 
no que se refere à geração de emprego, encontrada em trabalhos anteriores (Costa e Sampaio, 2003), e a correta percepção da população e de dirigentes municipais quando inqueridos sobre aspectos positivos da carcinicultura.

\section{Impactos na renda municipal}

O chamado efeito renda soma a renda gerada diretamente (podendo ser tomado o valor da produção ou o valor agregado, isto é, o valor líquido, sendo deduzidas as despesas), a renda indireta e a induzida. No caso de regiões e países, os efeitos indiretos e induzidos são quase integrais. Mas, em se tratando de municípios, os efeitos são limitados, pois as ligações impactam mais fortemente outros municípios, onde se localizam as empresas fornecedoras dos bens e serviços demandados pelas empresas ou consumidos pela população beneficiada.

No caso especifico da carcinicultura e dos municípios selecionados, todos os equipamentos importados. Os insumos mais destacados como rações, fertilizantes, e calcáreo, são produzidos fora desses municípios. A energia é de responsabilidade de empresa estadual com geração por empresa regional. Dessa forma, estima-se que as ligações intra-municipais respondem por apenas $2 \%$ do total do impacto indireto.

No que se refere ao efeito induzido, a renda que é gasta nos municípios limita-se quase exclusivamente ao valor pago em salários e ao percentual das despesas feitas no município. Assumiu-se que a renda líquida gerada pelas fazendas menores (menos de 10 hectares) é gasta nos municípios e que apenas no caso de Acaraú e Aracati, nos quais as sedes das empresas estão localizadas e exercem grande liderança local, a renda líquida é consumida no próprio município.

Somando-se o efeito direto, os efeitos indireto e os induzidos, obtém-se o efeito total, por município, expresso na Tabela 4, coluna 1. O efeito apropriado pelos municípios, mostrado na segunda coluna, é um percentual do total calculado, maior no caso de Acaraú e Aracati, devido à internalização da renda., sendo calculado com a matriz particionada (coluna 2).

O efeito total, como já destacado, não ocorre exclusivamente no município. Fica no município o valor agregado, sendo abatidas as trans- 
ferências (compras e pagamentos de serviços) para fora do município e seus rebatimentos. Por isso, no caso de municípios com menor PIB, como Cajueiro da Praia, Canguaretama, Pendências, Porto do Mangue e Jandaíra, o efeito total chega a exceder o PIB municipal estimado.

Analisando-se a participação da renda apropriada no município efeito intra-municipal - nota-se que a carcinicultura destaca-se pela elevada contribuição para o PIB municipal em Cajueiro da Praia, Porto de Mangue, Acaraú, Aracati, Pendências e Canguaretama. Ainda tem expressão no município de Jandaíra. Mas pouco representa para Itapissuma, Valença e Goiana. No caso particular de Cajueiro da Praia, o efeito calculado excede o PIB estimado, aventando-se duas hipóteses: parte da folha salarial é gasta fora do município, por funcionários que residem em outros municípios, predominantemente Parnaíba, grande centro regional; e/ou, o PIB estimado apresenta-se com viés para baixo.

Tabela 4. Efeito total (direto, indireto e induzido) e efeito no município (R\$ 1.000 de 2003)

\begin{tabular}{|l|c|c|c|c|}
\hline Município & Efeito Total & $\begin{array}{c}\text { Efeito } \\
\text { Intra-Municipal }\end{array}$ & $\begin{array}{c}\text { PIB } \\
\text { Municipal }\end{array}$ & \% do PIB \\
\hline Cajueiro da Praia & 21.015 & 2.726 & 2.216 & 123 \\
\hline Acaraú & 67.354 & 39.178 & 82.384 & 48 \\
\hline Aracati & 121.795 & 66.128 & 174.534 & 38 \\
\hline Canguaretama & 97.965 & 18.813 & 64.471 & 29 \\
\hline Pendências & 91.221 & 6.220 & 24.824 & 25 \\
\hline Porto de Mangue & 66.078 & 3.810 & 7.852 & 49 \\
\hline Goiana & 40.350 & 3.592 & 673.883 & 1 \\
\hline Itapissuma & 16.744 & 1.121 & 52.898 & 2 \\
\hline Valença & 44.321 & 5.698 & 201.781 & 3 \\
\hline Jandaíra & 41.543 & 5.033 & 36.029 & 14 \\
\hline
\end{tabular}

Fonte: Elaboração própria.

Destaca-se o nítido contraste entre o efeito total e a participação no PIB da renda apropriada no município. A diferença é marcante em Jandaíra, por exemplo. Como já analisado, esta diferença deve-se ao peso da indústria (produção e processamento do camarão cultivado) no município mas à retenção apenas da fração menor da renda final 
gerada no município. Com idêntico contraste, nota-se o enorme peso da carcinicultura em Pendências e Porto do Mangue, nos quais, mesmo retendo no município apenas parte do valor agregado, esta representa elevado percentual do PIB municipal.

Outro aspecto interessante decorre do tamanho relativo de cada município. O caso de Cajueiro da Praia é emblemático. Mesmo retendo apenas a folha salarial, dada a fragilidade da oferta de bens e serviços no município e o peso regional de Parnaíba, a carcinicultura é, de longe, a principal atividade, de fato, quase a única, componente do PIB municipal. No outro extremo, Goiana, município que é pólo na sua área de abrangência e possui comércio destacado e várias usinas de açúcar, a carcinicultura não agrega nem $1 \%$ ao PIB municipal.

Dada a expressiva participação da carcinicultura no PIB municipal, é de esperar que a expansão da criação de camarão tenha impacto na evolução do PIB $(\Delta \mathrm{Y})$. Para tal, compara-se a evolução do PIB municipal dos municípios selecionados com a da microrregião (Tabela 5). A hipótese é que tenha havido substancial expansão nos municípios onde a carcinicultura tem maior expressão: Cajueiro da Praia, Porto do Mangue, Acaraú, Aracati e, em situação intermediária, Pendências e Canguaretama. A análise dos dados da evolução do PIB mostra que este foi maior, em relação à microrregião, em Porto do Mangue, Canguaretama e Jandaíra. É semelhante em Acaraú e Aracati, mostrando que ocorreram, nestes dois municípios, mudanças outras, para menos, que compensaram a expansão gerada pela carcinicultura. No caso de Cajueiro da Praia, Valença, Itapissuma, Goiana e Pendências, o PIB municipal cresceu menos que o da microrregião. Para entender essas variações relativas, analisa-se em maior detalhe a evolução absoluta do PIB municipal.

Em Cajueiro da Praia, o PIB aumenta até 2001, mas apresenta queda em 2002 e 2003. A carcinicultura, de fato, apresenta recuo em período mais recente neste município e, sendo a principal responsável pela geração do PIB municipal, conduz à baixa do mesmo em relação à microrregião, que é fortemente influenciada pelo dinamismo de Paraíba.

Em Acaraú, o PIB apresenta maior valor em 1999, o que pode estar motivado por outra atividade que não a carcinicultura. De fato, o município teve importância na pesca de lagosta e peixe, atividades hoje 
quase extintas. A carcinicultura é atividade mais recente e deve ser a responsável pela elevação, em cerca de um terço, ocorrida em 2002 e 2003. No caso de Aracati, o crescimento do PIB é constante. Como Aracati é o grande pólo na microrregião Litoral de Aracati, o crescimento da microrregião é fortemente influenciado pelo que ocorre neste município. O contínuo crescimento, a partir de 2000, deve refletir na expansão da carcinicultura.

No Rio Grande do Norte, há crescimento constante em Canguaretama e Porto do Mangue, resultado que pode ser creditado, em boa parte, à carcinicultura. Tanto há crescimento absoluto como relativo na microrregião. Em Pendências, a maior fazenda tem acesso por Pendências mas recolhe e contribui para Porto do Mangue. Em período mais recente, várias fazendas, em Pendências, têm diminuído a produção.

Em Pernambuco, há crescimento absoluto do PIB em Goiana, mas em ambos os municípios do estado, o crescimento relativo é menor que na microrregião. Na microrregião da Mata Setentrional Pernambucana, a atividade central é a cana-de-açúcar, secundada pela banana e pelo comércio, atividades que apresentaram flutuações no período, inclusive no município de Goiana. Dado o pequeno peso da carcinicultura no município, as flutuações devem refletir outras influências. O mesmo pode ser dito em relação a Itapissuma, com o detalhe que a microrregião de Itamaracá reflete fortemente na evolução do PIB do município industrial de Igarassu, que responde por $90 \%$ do PIB da microrregião.

Na Bahia, Jandaíra destaca-se nitidamente na microrregião. O PIB é maior, tanto no município como na microrregião, em 2000, mas a evolução relativa é bem superior em Jandaíra. A carcinicultura, de enclave, tem pouca expressão na evolução do PIB. Em Valença, o município tem peso expressivo na microrregião, mas há diversas outras influências. Na chamada Costa do Dendê, observou-se a contração na produção de cacau, que chegou a ter destacada expressão no passado, flutuações na produção de dendê e da piaçava e expansão do turismo. De modo particular, a carcinicultura tem grande expressão na geração de emprego mas pouca participação na formação do PIB municipal. 
Tabela 5. Crescimento do PIB municipal - municípios selecionados e microrregião $(1999=100)$

\begin{tabular}{|l|l|c|c|c|c|c|}
\hline Município & Microrregião & 1999 & 2000 & 2001 & 2002 & 2003 \\
\hline Cajueiro da Praia & & 100 & 106 & 108 & 89 & 89 \\
\hline & Litoral Piauiense & 100 & 103 & 105 & 110 & 110 \\
\hline Acaraú & & 100 & 64 & 70 & 93 & 93 \\
\hline Aracati & Lit. de Cam. e Acaraú & 100 & 86 & 88 & 96 & 96 \\
\hline & & 100 & 100 & 103 & 110 & 110 \\
\hline Canguaretama & Litoral de Aracati & 100 & 102 & 105 & 112 & 112 \\
\hline & Litoral Sul & 100 & 118 & 127 & 147 & 146 \\
\hline Pendências & & 100 & 106 & 120 & 123 & 123 \\
\hline Porto do Mangue & & 100 & 133 & 108 & 100 & 100 \\
\hline & Vale do Açu & 100 & 120 & 138 & 143 & 143 \\
\hline Goiana & & 100 & 98 & 106 & 119 & 118 \\
\hline & Mata Setentrional & 100 & 98 & 103 & 109 & 109 \\
\hline Itapissuma & & 100 & 86 & 96 & 98 & 97 \\
\hline & Itamaracá & 100 & 93 & 100 & 102 & 102 \\
\hline Valença & & 100 & 97 & 101 & 93 & 96 \\
\hline & Valença & 100 & 103 & 109 & 98 & 106 \\
\hline Jandaíra & & 100 & 155 & 142 & 100 & 138 \\
\hline & Entre Rios & 100 & 103 & 101 & 90 & 100 \\
\hline
\end{tabular}

Fonte: Elaboração própria.

\section{Impactos na arrecadação municipal}

Os tributos municipais que incidem diretamente sobre a carcinicultura são limitados: o alvará de funcionamento e o ISS recolhido sobre serviços. Alguns municípios estabelecem a emissão de alvarás de funcionamento semestrais ou, mais freqüentemente, anuais, em valor fixo. Outros cobram alvará em função da área com viveiros. Por fim, há arrecadação de ISS - de modo geral $5 \%$ - sobre o valor dos serviços prestados. O valor desses tributos foi obtido diretamente nos municípios.

No caso das transferências federais e municipais, o efeito da atividade carcinicultora ocorre via agregação de valor. Tome-se o caso do ICMS. A legislação federal estabelece que, do total arrecadado, 25\% 
pertencem aos municípios. Desses $25 \%$, três quartos são repassados aos municípios em função do valor agregado. O valor agregado é estimado pela diferença entre as saídas e entradas, ou as vendas menos as compras, em cada município. Dessa forma, apurado o valor das vendas de camarão, em cada município, deduzidas as entradas (ração, póslarvas, compras de um modo geral), tem-se o valor agregado. Este valor é apurado mesmo que a atividade não recolha ICMS. O outro um quarto dos $25 \%$, ou seja, $6,25 \%$ do ICMS arrecadado, é distribuído aos municípios de acordo com legislação estadual, a qual, usualmente, leva em conta variáveis sociais ou socioambientais, servindo como estímulo ou como mecanismo de compensação para os municípios mais carentes.

A exportação de camarão é isenta, pela Lei $n^{\circ} .8796$ ou lei Kandir. As vendas internas são tributadas em $17 \%$. No entanto, os estados vêm concedendo benefícios fiscais que praticamente têm isentado a atividade. Em Pernambuco, é concedido crédito de 16,84\%, com a carga reduzindo-se a $0,16 \%$, sobre um valor de pauta de $\mathrm{R} \$ 10,00 / \mathrm{kg}$. No Ceará, há isenção completa. No Rio Grande do Norte, as transações internas recebem crédito integral, mas as vendas inter-estaduais vêm sendo, recentemente, taxadas em $12 \%$, sobre um valor de pauta de R \$ 10,00/kg, com o propósito de estimular o processamento e a exportação pelo próprio estado. Na Bahia, é concedido crédito de $75 \%$ do ICMS, nas operações internas e inter-estaduais. O Piauí também concede crédito que implica em isenção.

Ressalte-se que mesmo não havendo tributação, é apurado o valor agregado, para efeito da redistribuição aos municípios de 18,75\% do valor arrecadado. Embora os municípios não identifiquem claramente o efeito da carcinicultura no valor do repasse do ICMS, tomando-se a derivada da cota do ICMS em função do valor agregado adicional pelo município, tem-se:

$$
\left.\frac{\partial(\text { Cota ICMS }}{\partial \mathrm{Va}_{\mathrm{i}}}\right)=\frac{\mathrm{ICMS} .0,1875\left[\Sigma \mathrm{Va}_{\mathrm{i}}+\mathrm{Va}_{\mathrm{i}} /\left(\Sigma \mathrm{Va}_{\mathrm{i}} \mathrm{I}^{2}\right]\right.}{\left(\Sigma \mathrm{Va}_{\mathrm{i}}\right)^{2}}
$$

em que $\mathrm{Va}_{\mathrm{i}}$ é o valor agregado pelo município $\mathrm{i}^{4}$.

\footnotetext{
${ }^{4}$ Toma-se como exemplo um município que contribua com $1 \%$ do Valor Agregado estadual. Assumindo-se que gere um Valor Agregado igual a R $\$ 10$ e que o Valor Agregado do estado seja $\mathrm{R} \$ 1.000$, tem-se um repasse de $\mathrm{R} \$ 0,30$ para um repasse total de $\mathrm{R} \$ 30,15$. Assuma agora que o Valor Agregado do município aumente $50 \%$, de $\mathrm{R} \$ 10$ para $\mathrm{R} \$ 15$,
} 
A variação na cota de ICMS depende: (a) da variação na arrecadação total, a qual depende da variação na circulação de mercadorias no estado como um todo e (b) da variação no percentual do município, o qual depende da variação do valor agregado pelo município em relação ao valor agregado total,

$$
\operatorname{Var}\left(\mathrm{ICMS}_{\mathrm{i}}\right)=\operatorname{Var}(\mathrm{ICMS} \text { total})+\operatorname{Var}(\text { do \% do Município i) }
$$

sendo Var (ICMS total) = f (arrecadação total) e a Var (do \% do município i) $=\mathrm{g}$ (valor agregado pelo município e pelo total de municípios)

No caso das exportações, os estados e municípios são compensados pela renúncia da taxação. É o caso do camarão. Mas, novamente, como no ICMS, só $18,75 \%$ do valor recebido como compensação é repassado ao município.

Uma análise mais ampla das finanças municipais mostra que entre $70 \%$ e $95 \%$ da receita orçamentária é proveniente das transferências da União e do Estado. A receita tributária representa entre $2 \%$ e $5 \%$, não estimulando o município a ampliar a arrecadação direta. Nas transferências, destaca-se o Fundo de Participação dos municípios, da parte da União (FPM), a cota-parte do ICMS, da parte do Estado, e o Fundef, este em período mais recente.

Na Tabela 6, encontra-se o valor do tributo direto da carcinicultura (alvará somado ao valor estimado do ISS, este calculado tomando a média das despesas com serviços ${ }^{5}$ ) e seu percentual em relação à receita tributária total. Fica evidente que não há maior esforço em aumentar a arrecadação direta da atividade. A arrecadação direta tem maior expressão em municípios menores, nos quais a arrecadação de ISS (o mais importante tributo direto) é limitada, pela fragilidade da economia e do comércio local. É o caso de Porto do Mangue, Cajueiro da Praia e Jandaíra. Os municípios de Acaraú e Pendências apresentam uma participação menos expressiva, mas ainda significante. A exceção é Aracati, que aprovou tabela de alvará que eleva bastante a arrecadação direta.

devido à expansão da carcinicultura, o que mantém o valor do ICMS arrecado e repassado aos municípios constante. No entanto, esse município em particular receberá, agora, um repasse de $\mathrm{R} \$ 0,45$, ou seja, a sua participação no repasse total aumentou em $50 \%$.

${ }^{5} \mathrm{O}$ percentual é de $5 \%$, com exceção de Aracati, onde é de $3 \%$. 
Nos outros municípios, a arrecadação proveniente da carcinicultura fica em torno de $3 \%$.

Tabela 6. Contribuição da carcinicultura na receita tributária do município, em R\$

\begin{tabular}{|l|c|c|c|c|}
\hline Município & Alvarás & ISS & Total & \% da Rec. Tributária** \\
\hline Cajueiro da Praia & 500 & 17.791 & 18.291 & 30,0 \\
\hline Acaraú & 3.360 & 57.021 & 60.381 & 10,1 \\
\hline Aracati & 85.986 & 62.364 & 148.350 & 11,7 \\
\hline Canguaretama & $*$ & 82.938 & 82.938 & nd \\
\hline Pendências & $*$ & 77.227 & 77.227 & 14,5 \\
\hline Porto do Mangue & 3.600 & 55.941 & 59.541 & 58,2 \\
\hline Goiana & 1.326 & 34.160 & 35.486 & 3,3 \\
\hline Itapissuma & $*$ & 14.176 & 14.176 & 2,8 \\
\hline Valença & 1.142 & 37.521 & 38.663 & 3,3 \\
\hline Jandaíra & $*$ & 36.376 & 36.376 & 25,6 \\
\hline
\end{tabular}

Fonte: Elaboração própria.

*Autorizado por lei municipal mas não cobrado.

${ }^{*}$ Calculado, por aproximação, em relação à receita de 2002.

Deve-se destacar que a arrecadação de ISS assume expressão bem maior quando da construção dos viveiros, já que a maior despesa refere-se a serviços contratados para execução das obras. Já na operação das fazendas, laboratórios e centros de processamento, os serviços contratados referem-se a transporte e outros serviços de menor magnitude e tem pequena expressão nos gastos totais. Não foi calculado o impacto sobre o ISS considerando o período de construção, por ser transitório, mas este assume grande expressão. Em Aracati, por exemplo, considera-se um valor de $\mathrm{R} \$ 50.000,00$ para construção de um hectare de viveiro, sendo que $60 \%$ desse valor é considerado como base de cálculo do valor tributável para o ISS, com alíquota de $3 \%$, o que gera uma receita de $\mathrm{R} \$ 900,00 /$ hectare. Para uma área em operação, em 2003, de 1.030 hectares, tem-se um valor de $\mathrm{R} \$ 927.000,00$ recolhido de ISS, ou cerca de $73 \%$ da receita tributária anual desse município.

Na Tabela 7, é apresentada a evolução da cota-parte do ICMS, em 
valores correntes, para o período que corresponde à expansão da carcinicultura. Em alguns municípios, o grande crescimento do ICMS chama a atenção: Pendências, Itapissuma, Valença, Jandaíra. Acreditase que esse crescimento reflita predominantemente o aumento do valor agregado que, no caso desses municípios, representa a expansão da carcinicultura.

Tabela 7. Evolução da cota-parte do ICMS, em R $\$ 1.000$

\begin{tabular}{|l|c|c|c|c|c|c|c|}
\hline Município & 1996 & 1997 & 1998 & 1999 & 2000 & 2001 & 2002 \\
\hline Cajueiro da Praia & $\mathrm{nd}$ & 16 & $\mathrm{Nd}$ & $\mathrm{Nd}$ & $\mathrm{nd}$ & 82 & $\mathrm{nd}$ \\
\hline Acaraú & 1.026 & 1000 & $\mathrm{Nd}$ & $\mathrm{Nd}$ & 1.142 & 1246 & 1.472 \\
\hline Aracati & 2.332 & 2.658 & 2.166 & 2.201 & 1.805 & 2.665 & 3.825 \\
\hline Canguaretama & 584 & 704 & $\mathrm{Nd}$ & $\mathrm{Nd}$ & $\mathrm{nd}$ & $\mathrm{nd}$ & $\mathrm{nd}$ \\
\hline Pendências & 827 & 752 & $\mathrm{Nd}$ & 988 & 1.021 & 1.541 & 1.882 \\
\hline Porto do Mangue & $\mathrm{nd}$ & $\mathrm{nd}$ & $\mathrm{Nd}$ & $\mathrm{Nd}$ & $\mathrm{nd}$ & $\mathrm{nd}$ & $\mathrm{nd}$ \\
\hline Goiana & 6.143 & 6.620 & $\mathrm{Nd}$ & $\mathrm{Nd}$ & 9.569 & 10.220 & $\mathrm{nd}$ \\
\hline Itapissuma & 4.345 & $\mathrm{nd}$ & $\mathrm{Nd}$ & $\mathrm{Nd}$ & 6.531 & 7.803 & 10.141 \\
\hline Valença & $\mathrm{nd}$ & 1.382 & 1.114 & 1.442 & 1.850 & 2.266 & 3.802 \\
\hline Jandaíra & $\mathrm{nd}$ & 190 & 328 & $\mathrm{Nd}$ & $\mathrm{nd}$ & 736 & 1.501 \\
\hline
\end{tabular}

Fonte: Elaboração própria.

A cota-parte do ICMS, como apresentada, varia com a arrecadação total e com a variação da participação do município no valor total agregado, este dependente, em parte, da expansão das atividades no município. É possível inferir quanto à evolução das duas variações ao se comparar o crescimento do ICMS total do estado com o da cota-parte do município. Até 2000, em nenhum município a cota-parte cresce a taxa maior que o total do ICMS. A partir de 2000, o quadro se inverte: o crescimento é bem superior em Aracati, Pendências, Itapissuma, Valença e Jandaíra; a exceção é Goiana (Tabela 8), onde a atividade principal, o açúcar, entra em crise. Esses dados mostram que a variação do valor agregado do município é a principal responsável pela elevação da cota-parte do ICMS. A magnitude da variação mostra que o impacto é substancial.

O impacto da expansão do valor agregado da carcinicultura sobre a 
cota-parte do ICMS não é reconhecido nos municípios. Nas entrevistas, não houve uma única menção a este importante impacto indireto na receita do município. Mas, como visto, este impacto é expressivo.

Tabela 8. Crescimento do ICMS do estado e da cota-parte municipal, \%

\begin{tabular}{|l|c|c|c|c|}
\hline Estado/Município & $1999 / 98$ & $2000 / 99$ & $2001 / 00$ & $2002 / 01$ \\
\hline CE & 15,1 & 46,2 & 16,6 & 26,6 \\
\hline Acaraú & - & - & 9,1 & 26,5 \\
\hline Aracati & 1,6 & $-18,0$ & 47,6 & 43,5 \\
\hline RN & 13,7 & 51,00 & 33,5 & 12,0 \\
\hline Pendências & - & 3,3 & 50,9 & 22,1 \\
\hline PE & 6,7 & 45,4 & 15,4 & $-3,7$ \\
\hline Goiana & - & - & 6,8 & - \\
\hline Itapissuma & - & - & 19,5 & 30,0 \\
\hline BA & 83,0 & 74,6 & 9,7 & $-11,3$ \\
\hline Valença & 29,4 & 28,3 & 22,5 & 67,8 \\
\hline Jandaíra & - & - & - & 103,9 \\
\hline
\end{tabular}

Fonte: Elaboração própria.

Obs. Para três municípios não há dados disponíveis.

Adicionalmente, como as exportações de camarão são isentas, há compensação aos estados e municípios pela perda de arrecadação. É a cota do Fundo de Exportação (FPEX) (União) e mais recentemente as cotas da Lei $n^{\circ} .8796$ do ICMS (União) e do IPI exportação (Estado). Estas duas cotas aumentam com a expansão da produção e do processamento do camarão para exportação. Analisando-se a evolução dessas cotas, para vários municípios, para os quais se dispõe de uma série mais completa, o crescimento é expressivo para Aracati, Jandaíra, Pendências, Itapissuma. Embora o valor total seja pequeno, em relação à receita orçamentária total do município, é expressivo quando se toma em relação à receita tributária. Para o ano de 2002 (2001, para Cajueiro da Praia), por exemplo, tem-se: $41 \%$ para Itapissuma, $38 \%$ para Cajueiro da Praia, $31 \%$ para Jandaíra, 10\% para Valença, 9\% para Pendências, $8 \%$ para Aracati e 6,5\% para Acaraú. Estas participações são bem superiores às obtidas com a arrecadação direta (alvará e ISS), com exceção 
de Pendências e Aracati. Ou seja, a compensação pela renúncia da tributação das exportações agrega mais à receita orçamentária que toda a tributação direta da carcinicultura. Por contraste, municípios produtores mas que não devem figurar como exportadores, como parece ser o caso de Goiana, nada agregam à receita municipal neste item.

Em resumo, a criação do camarão marinho cultivado impacta na arrecadação municipal principalmente na cota-parte do ICMS e na cota do fundo de compensação das exportações e, em menor escala, na receita tributária, via alvarás de funcionamento e recolhimento de ISS. Destaca-se a importância do processamento no município ou da identificação do mesmo nas exportações, que o qualificam para receber a cota do fundo de compensação das exportações. Ressalta-se, igualmente, o exemplo do município de Aracati que, com nova pauta de contribuições, conseguiu expandir bastante a receita tributária.

\section{Considerações finais}

A análise empreendida, com utilização de metodologia pioneira para isolar impactos em termos municipais, permite iluminar os impactos da carcinicultura no emprego, na renda e na arrecadação municipal. Há impactos visíveis e plenamente reconhecidos em termos municipais e impactos pouco visíveis e reconhecidos mas de substancial importância.

Há pleno reconhecimento quanto à destacada contribuição ao emprego, formal e total. A participação no emprego formal é de grande magnitude, mostrando que o fato de a maioria do emprego nas fazendas ser formal e estável traz grande estabilidade para o mercado de trabalho local. O emprego total geral é de grande importância nos municípios menores, nos quais a carcinicultura é, de longe, o maior empregador, mesmo não ocorrendo quase impacto indireto e induzido. Maior seria caso o comércio desses municípios fosse expandido e se a produção local desenvolvesse maiores vínculos com o município, isto é, as ligações para trás e para adiante fossem reforçadas. Nos municípios onde esses vínculos são mais sólidos, boa parte do emprego induzido ocorre dentro do município, em decorrência da retenção da renda e do seu gasto, no município.

O impacto na renda municipal é menos visível mas ainda recon- 
hecido por alguns. Ressalte-se novamente que o efeito no município é apenas uma fração do efeito renda total. Ou seja, a contribuição para a renda regional é muitas vezes superior, principalmente quando se trata de municípios pequenos, com comércio limitado, nos quais não ocorre processamento do camarão e a sede das empresas fica situada fora do município. Com tudo isso, e novamente com maior força nos municípios menores, nos quais a carcinicultura representa parcela maior do PIB, a renda gerada tem expressiva participação no PIB municipal. Em alguns desses municípios, a carcinicultura tem sido determinante para o crescimento mais rápido do PIB.

O impacto na arrecadação municipal não é visível nem reconhecido na maioria dos municípios. Isso se deve a várias causas:

a) À pequena participação da receita tributária na receita orçamentária. Em conseqüência, há desestímulo ao aumento da arrecadação. Este é um erro, pois a arrecadação marginal (adicional) pode propiciar meios para a implantação de projetos sociais com maior independência e iniciativa dos municípios;

b) À falta de clareza quanto à relação entre o valor agregado e a cotaparte do ICMS. Como demonstrado, apesar de indireta, essa relação é bem nítida. E, no caso, embora através de comprovação indireta, pode-se afirmar que, na maioria dos municípios, a carcinicultura foi capaz de elevar a cota-parte do município, contribuindo para o aumento das transferências e, em última análise, da receita orçamentária. Essa contribuição não é visível e, em conseqüência, não é reconhecida. No entanto, pode ser anotada como mais uma destacada contribuição da carcinicultura ao município.

c) À completa ausência de análise da contribuição da carcinicultura de exportação para o aumento dos repasses compensatórios da isenção de tributos das exportações. Apesar do valor não ser elevado, em relação às outras transferências, representa aporte adicional de recursos às finanças municipais.

Pode-se concluir que a carcinicultuta vem contribuindo, de forma predominantemente indireta, para elevação da receita orçamentária dos municípios.

Em conseqüência, há evidências que permitem concluir que a carcinicultura, nos municípios analisados, contribui de forma muito posi- 
tiva para a elevação e a estabilidade do emprego e da renda, para a elevação da receita municipal e para a melhoria das condições de vida nos municípios.

\section{Referências bibliográficas}

ABCC - Associação Brasileira dos Criadores de Camarão. Censo da Carcinicultura Brasileira - 2003, Relatório Final, 2003.

ABCC. Revista da ABCC. Recife, vários números.

Azzoni, C. R., D. Kadota, E. A Hadad e M.T. Rodriguez. Macroeconomia do Nordeste: 1970-1998. Fortaleza, Banco do Nordeste, 2001.

Costa, E. F. e Y. Sampaio. Geração de Empregos Diretos e Indiretos na Cadeia Produtiva do Camarão Marinho Cultivado. Revista Economia Aplicada, 8 (2), 1-19, 2004.

Costa, E.F., Y. Sampaio e E. Albuquerque. A Carcinicultura Brasileira: Expansão Recente e Perspectivas no Comércio Mundial. Revista Brasileira de Comércio Exterior, 8 (out/dez), 86-95, 2004.

IBGE. Censo Demográfico, www.ibge.gov.br, acesso em 2005.

Leite, J.A A . Macroeconomia. Cap. 6 - Instrumentos de Política Fiscal, 203-246, São Paulo, Editora Atlas, 2000.

Ministério do Trabalho. Dados da RAIS, www.rais.gov.br, acesso em 2005.

Ministério da Fazenda. www.fazenda.gov.br, acesso em 2005.

Rocha, I., J. Rodrigues e L. Amorim. A Carcinicultura Brasileira em 2003. Revista da ABCC, 6(1), 30-36, março 2004.

Rodriguez, M.T. e J.J. M. Guilhoto. Eficiência Alocativa do Fundo Constitucional de Financiamento do Nordeste (FNE) - Uma visão de insumo-produto. Revista Econômica do Nordeste, 29 (3), 319-348, 1998.

Souza Júnior, J.P., Análise da Eficiência da Produção de Camarão 
Marinho em Cativeiro no Estado do Ceará. Dissertação de Mestrado. Programa de Pós-Graduação em Economia Rural, Universidade Federal do Ceará, 127 p., Fortaleza, 2004.

Vergolino, J. R. e G. M. Gomes. Estimação dos PIBS Municipais para Municípios do Brasil. Brasília-DF, IPEA, 1999. 